Pharmaceutics, Drug Delivery and Pharmaceutical Technology

\title{
In Vivo Performance of Fenofibrate Formulated With Ordered Mesoporous Silica Versus 2-Marketed Formulations: A Comparative Bioavailability Study in Beagle Dogs
}

\author{
Katarina Bukara 1, 2, *, Laurent Schueller ${ }^{3}$, Jan Rosier ${ }^{3}$, Tinne Daems ${ }^{3}$, Loes Verheyden ${ }^{3}$, \\ Siemon Eelen ${ }^{3}$, Johan A. Martens ${ }^{4}$, Guy Van den Mooter ${ }^{5}$, Branko Bugarski ${ }^{2}$, \\ Filip Kiekens ${ }^{1}$ \\ ${ }^{1}$ Laboratory for Pharmaceutical Technology and Biopharmacy, University of Antwerp, Universiteitsplein 1, Wilrijk B-2610, Belgium \\ ${ }^{2}$ Department of Chemical Engineering, Faculty of Technology and Metallurgy, University of Belgrade, Belgrade, Serbia \\ ${ }^{3}$ Formac Pharmaceuticals NV, Gaston Geenslaan 1, Heverlee B-3001, Belgium \\ ${ }^{4}$ Center for Surface Chemistry and Catalysis, KU Leuven, Kasteelpark Arenberg 23, Heverlee B-3001, Belgium \\ ${ }^{5}$ Drug Delivery and Disposition, University of Lueven (KU Leuven), O\&N2, Herestraat 49, box 921, Leuven B-3000, Belgium
}

\section{A R T I C L E I N F O}

\section{Article history:}

Received 1 March 2016

Revised 10 May 2016

Accepted 10 May 2016

Available online 28 June 2016

\section{Keywords:}

ordered mesoporous silica

fenofibrate

poor solubility

dissolution

oral bioavailability

\begin{abstract}
A B S T R A C T
The present study aims to evaluate the in vitro and in vivo performance of ordered mesoporous silica (OMS) as a carrier for the poorly water-soluble compound fenofibrate. Fenofibrate was loaded into OMS via incipient wetness impregnation to obtain a $29 \%$ drug load and formulated into capsules. Two capsule dosage forms (containing 33.5 and $16.75 \mathrm{mg}$ fenofibrate, respectively) were compared with the commercially available forms-Lipanthyl ${ }^{\circledR}$ (fenofibrate microcrystals) and Tricor $^{\circledR}$ (fenofibrate nanocrystals). In vitro dissolution tests showed that the amount of fenofibrate released from Lipanthyl ${ }^{\circledR}$ and Tricor $^{\circledR}$ was approximately $30 \%$, whereas approximately $66 \%$ and $60 \%$ of the drug was released from OMS capsules containing 33.5 and $16.75 \mathrm{mg}$ of fenofibrate, respectively. Storage of OMS capsules loaded with $33.5 \mathrm{mg}$ of fenofibrate at $25^{\circ} \mathrm{C} / 60 \%$ relative humidity ( $\mathrm{RH}$ ) or $40^{\circ} \mathrm{C} / 75 \% \mathrm{RH}$ did not alter the release kinetics, nor the physical state of the compound, pointing the stability of the present formulation. The in vivo study in dogs confirmed satisfying level of safety and tolerability of fenofibrate-OMS formulation (eq. $33.5 \mathrm{mg}$ ) with the potential to improve the absorption of fenofibrate. Though some variability in the data, this formulation is promising to be further investigated in a clinical trial setting.
\end{abstract}

๑) 2016 American Pharmacists Association ${ }^{\circledR}$. Published by Elsevier Inc. All rights reserved.

\section{Introduction}

Fenofibrate is a highly lipophilic drug used to normalize the plasma titer of low-density lipoproteins and cholesterol in patients with hypercholesterolemia and hypertriglyceridemia. ${ }^{1,2}$ As a typical Biopharmaceutical Classification System class 2 compound $(\log p=5.24)$, it is virtually insoluble in water and physiological fluids. ${ }^{3}$ Its insufficient absorption from the aqueous environment of the gastrointestinal tract results in very low systemic exposure after oral administration. ${ }^{1}$ Thus, oral bioavailability of fenofibrate may be improved by increasing its aqueous solubility. ${ }^{4}$ Although over the past few years, several conventional formulation techniques, such as micro- and nanonization, ${ }^{5}$ formation of liposomes, ${ }^{6}$ various

\footnotetext{
* Correspondence to: Katarina Bukara (Telephone: +32-0-3-265-26-87).

E-mail address: katarinabukara@gmail.com (K. Bukara).
}

polymeric nanoparticulated systems, ${ }^{4}$ and lipid-based formulations, ${ }^{7}$ have been employed to enhance the oral bioavailability of fenofibrate, the number of marketed applications of these technologies remains very limited.

Ordered mesoporous silica (OMS) is a promising strategy to increase the apparent aqueous solubility, dissolution rate, and dissolution rate of poorly water-soluble entities. ${ }^{8}$ Mellaerts et al. ${ }^{9}$ were the first to correlate the increased release rate of itraconazole from OMS with an increase in bioavailability and demonstrated a performance comparable to that of the marketed product Sporanox. OMS with a pore size ranging from 4 to $10 \mathrm{~nm}$ in diameter, large specific pore volume (approximately $1 \mathrm{~cm}^{3} / \mathrm{g}$ ) and surface area (approximately $1000 \mathrm{~m}^{2} / \mathrm{g}$ ) ${ }^{10}$ provides high drug load and increase in dissolution rate of active pharmaceutical ingredients (APIs) to the highest possible level. ${ }^{11}$ The principle of the dissolution improvement is based on the adsorption of an API onto the surface of the carrier material in a molecular manner. ${ }^{12}$ Since 
the deposition of an API in the mesopores of the carrier is associated with the suppression of crystallization of the entrapped molecules, mesoporous silica materials are excellent stabilizers for amorphous APIs. ${ }^{11}$ When exposed to water, the adsorbed drug molecules compete for the hydrophilic silica surface and are released from the pores. Consequently, in this "dissolved" state, they become available for absorption in the gastrointestinal tract. ${ }^{13}$

The ability of mesoporous silica to improve the dissolution profile of fenofibrate in biorelevant media has already been described in literature. ${ }^{14-16}$ However, in this study, for the first time, the biopharmaceutical performance of OMS-based formulations was determined in dogs by comparing the oral bioavailability of fenofibrate loaded onto OMS material with 2-marketed formulations: Lipanthyl ${ }^{\circledR}$ (microcrystals of fenofibrate) and Tricor $^{\mathbb{R}}$ (nanocrystals of fenofibrate). The results indicate that OMS could be a potential carrier to achieve enhanced oral bioavailability for fenofibrate. Moreover, it provides valuable information about formulation selection to be used for further in vivo testing, in humans.

\section{Materials and Methods}

\section{Ordered Mesoporous Silica}

OMS material was synthesized according to the synthesis procedure described by Jammaer et al. ${ }^{17}$ Briefly, a citric acid-buffered solution, Pluronic ${ }^{\circledR}$ P123 (BASF, Ludwigshafen, Germany), was prepared overnight. To this surfactant solution, a sodium silicate solution was added, and the mixture was stirred. The final synthesis mixture was kept nonstirred $24 \mathrm{~h}$ at room temperature followed by $48 \mathrm{~h}$ at $75^{\circ} \mathrm{C}$. The material is then filtered, washed with deionized water, and dried. Finally the OMS material was calcined under ambient conditions at $550^{\circ} \mathrm{C}$.

\section{Fenofibrate-Loading Procedure}

Loading of fenofibrate into the OMS material was carried out with an automated granulator (Mipro 900; ProCepT, Zelzate, Belgium). Pure API (8.19 g) was dissolved in $80 \mathrm{~mL}$ of dichloromethane. The API solution was filtered through a $0.45-\mu \mathrm{m}$ polytetrafluoroethylene (PTFE) filter and added to the OMS in the granulator bowl in 2 steps using an atomization nozzle. Each dosing step was followed by a drying step $\left(30^{\circ} \mathrm{C}\right)$ of $45 \mathrm{~min}$. The loading of the OMS was $29 \%(\mathrm{w} / \mathrm{w})$ of API. The loaded material was further dried for 3 days in circulating air oven at $25^{\circ} \mathrm{C}$ to remove residual dichloromethane.

\section{Drug Load Quantification}

To determine the amount of fenofibrate loaded into the OMS, approximately $7.5 \mathrm{mg}$ of the loaded silica was weighed in a volumetric flask of $25.0 \mathrm{~mL}$. Dimethyl sulfoxide $(5.0 \mathrm{~mL})$ was added and then filled up with acetonitrile. The suspension was sonicated for $30 \mathrm{~min}$ in a Branson 8200 ultrasonic bath, filtered afterward using a $0.45-\mu \mathrm{m}$ PTFE membrane filter (VWR International) and analyzed with high-performance liquid chromatography (HPLC) with UV detection.

\section{Dosage Form}

The fenofibrate-loaded OMS was blended with silicified microcrystalline cellulose (Prosolv ${ }^{\circledR}$ HD 90; JRS Pharma) and croscarmellose sodium (Ac-Di-Sol ${ }^{\mathbb{R}}$; FMC Biopolymer, Philadelphia, PA); Table 1. Blending was performed in the MiPro Granulator. Two capsule formulations (eq. 33.5-mg fenofibrate and eq. 16.75-mg
Table 1

Compositions of Fenofibrate-Loaded OMS Capsules

\begin{tabular}{|c|c|c|}
\hline \multirow[t]{2}{*}{ Dosage Form } & \multicolumn{2}{|c|}{ Formac OMS Capsules } \\
\hline & Eq. $33.5 \mathrm{mg}(\%)$ & Eq. $16.75 \mathrm{mg}(\%)$ \\
\hline $\begin{array}{l}\text { Fenofibrate-loaded OMS } \\
\text { Acetone }^{a}\end{array}$ & 57.76 & 50.20 \\
\hline Sodium crosscaramelose & 10.00 & 10.00 \\
\hline Silicified microcrystalline cellulose & 32.34 & 39.80 \\
\hline
\end{tabular}

${ }^{\text {a }}$ Not present in the final formulation.

fenofibrate) were compared with the commercially available forms Lipanthyl ${ }^{\circledR}$ and Tricor $^{\circledR}$. All formulations were evaluated in vitro before the in vivo dog study.

\section{In Vitro Dissolution Study}

To study the release of fenofibrate out of the OMS carrier, the loaded formulations were suspended in 900-mL 0.1 N HCl (VWR Prolabo, Radnor, PA) + 0.1\% Tween 80 (Acros Organics, Geel, Belgium). Dissolutions were performed using a Hanson Vision ${ }^{\circledR}$ Elite 8 dissolution apparatus (USP II-Paddle). The paddle speed was set at $50 \mathrm{rpm}$. The experiment was performed at $37^{\circ} \mathrm{C}$. Samples of $1.0 \mathrm{~mL}$ were taken at 5, 10, 15, 30,60, and $120 \mathrm{~min}$ and filtered over a $0.45-\mu \mathrm{m}$ PTFE membrane filter (VWR International). The volume withdrawn is replaced by the same amount of fresh medium. The samples were diluted and analyzed using HPLC with UV detection (see below).

\section{High-Performance Liquid Chromatography}

Measurements of the assay and in vitro dissolution samples were performed using an isocratic HPLC method. The HPLC system was a VWR Hitachi Elite LaChrom with an L-2200 UV detector set at $287 \mathrm{~nm}$. The analytical column used is a Lichrospher 60 (125-4,6 mm; $5 \mu \mathrm{m})$. A mobile phase made up of 25-mM ammonium acetate buffer $\mathrm{pH} 3.5 /$ acetonitrile (30:70; v:v) with a flow rate of $1 \mathrm{~mL} / \mathrm{min}$ was used. The column temperature was set at $30^{\circ} \mathrm{C}$, and the injection volume was $20 \mu \mathrm{L}$.

\section{Analysis of Plasma Samples}

A bioanalytical method was used for the quantification of fenofibrate and fenofibric acid in the dog oxalate plasma in the range of $0.02-4.00 \mathrm{ng} / \mathrm{mL}$ and of $10.00-2000.00 \mathrm{ng} / \mathrm{mL}$, respectively. The dog plasma samples were thawed at room temperature, homogenized, and centrifuged. Fifty microliters of supernatant was mixed with $450 \mu \mathrm{L}$ of a solution of the internal standard (fenofibrate-d6 [0.05 ng/mL] and fenofibric acid-d6 [1250 ng/mL]) in acetonitrile and subsequently centrifuged at high speed. For the analysis of fenofibric acid, $50 \mu \mathrm{L}$ of the elution was then transferred to a 96-well plate, mixed with acetonitrile/water $(90: 10 \mathrm{v} / \mathrm{v})$, shaken for $5 \mathrm{~min}$, and then $6.0 \mu \mathrm{L}$ was injected into ultra-performance liquid chromatography tandem mass-spectrometry system. For the analysis of fenofibrate, the rest of the elution was evaporated at $50^{\circ} \mathrm{C}$, dissolved in $50 \mu \mathrm{L}$ acetonitrile/water (90:10 v/v), shaken for $5 \mathrm{~min}$, and then $10.0 \mu \mathrm{L}$ was injected into ultra-performance liquid chromatography tandem mass-spectrometry system. The targeted compounds were analyzed on ACQUITY ultra-performance liquid chromatography BEH C18 column $(50 \times 2.1 \mathrm{~mm}, \mathrm{dp}=$ $1.7 \mu \mathrm{m})$, applying acetonitrile:water:ammonium acetate (10:85:5, $\mathrm{v} / \mathrm{v} / \mathrm{v})$ and $(90: 5: 5, \mathrm{v} / \mathrm{v} / \mathrm{v})$ in the linear gradient mode as mobile phase. Quantitation method was based on peak area ratio, and the response versus concentration data were fitted using quadratic regression with $1 / x^{2}$ weighting. 
In Vivo Studies

Pharmacokinetic (PK) parameters were evaluated after single oral administration in 4 male Beagle dogs (31-36 months old, body weight range $=10.8-11.8 \mathrm{~kg}$; Marshall BioResources, North Rose, NY).

From all animals, approximately $4 \mathrm{~mL}$ of blood samples were taken from the jugular vein using vacutainers and potassium oxalate/sodium fluoride (Greiner Bio-One, Bad Haller, Austria) as an anticoagulant. Blood was sampled at predose and 0.5, 1, 1.5, 2, 4, 6, 8,12 , and $24 \mathrm{~h}$ after dosing. Within $30 \mathrm{~min}$ after sampling, blood was centrifuged at $5^{\circ} \mathrm{C}$. Immediately after centrifugation, plasma was stored in labeled polypropylene tubes at $-75^{\circ} \mathrm{C}$ before analysis.

This study protocol was reviewed and agreed by the Animal Welfare Officer and the ethical Committee of NOTOX (00-34) as required by the Dutch Act on Animal Experimentation (February 1997). The animals were treated in accordance with the Directive 2010/63/EU.

The study procedures were based on the following guidelines, recommendations, and requirements:

- Workshop/conference report-Quantitative bioanalytical methods validation and implementation: best practices for chromatographic and ligand binding assays. C. T. Viswanathan et al., The AAPS Journal, 9, 2007, E30-E42.

- Guidance for industry: bioanalytical method validation. US Department of Health and Human Services, Food and Drug Administration, Center for Drug Evaluation and Research and Center for Veterinary Medicine, May 2001.

All PK parameters were calculated from the curves constructed from individual animals, using the WinnonLin 5.2 program. Noncompartmental analysis was applied using the extravascular model. The lower limit of quantification (LLOQ) of fenofibrate was 0.020 $\mathrm{ng} / \mathrm{mL}$, and for fenofibrate acid, the LLOQ was $10.00 \mathrm{ng} / \mathrm{mL}$. All values below the LLOQ after $C_{\max }$ were excluded from the PK evaluation. If a value was below the LLOQ before $C_{\max }$, than this value was set to $0 \mathrm{ng} / \mathrm{mL}$. In case several intermediate not quantifiable concentrations were present, all not quantifiable concentrations and all following time points were excluded from the kinetic evaluation. In case 1 intermediate not quantifiable concentration was present, this time point was excluded was excluded from the kinetic evaluation. Nominal sampling times were used (deviations were $<20 \%$ ).

The following PK parameters were calculated:

- $\mathrm{C}_{\max }$ - maximum observed plasma concentration.

- $\mathrm{C}_{\text {last}}$-last measurable plasma concentration.

- $t_{\max }$ - time point at which maximum plasma concentration was reached and assessed directly from the data.

- $t_{\text {last }}$-time point of last measurable plasma concentration.

- AUC last-area under the plasma concentration-time curve from time of administration until the last measurable plasma concentration $\left(t_{\text {last }}\right)$, calculated using the linear trapezoidal rule (for both parent and metabolite).

- AUC $_{\infty}$ - area under the curve after a single dose from time of administration until infinity, calculated as $\mathrm{AUC}_{\text {last }}+\mathrm{C}_{\text {last }} / \lambda_{\mathrm{z}}$, where $C_{\text {last }}$ is the last measurable concentration. If the data set did not allow extrapolation to infinity, then the AUC up to the last measurable time point was calculated. Extrapolations of $>15 \%$ of the total AUC were reported as approximation.

- $\lambda_{z}$-elimination rate constant, determined by linear regression of the terminal points of the in-linear concentration-time curve.

- $t_{1 / 2}$-elimination half-life, calculated as $\ln (2) / \lambda_{z}$. The following requirements had to be met for an acceptable calculation of $t_{1 / 2}$.
1. at least 3 time points had to be available to be used in the calculation.

2. correlation coefficient $\left(R^{2}\right)$ was at least 0.9 .

3. span of time points used in $t_{1 / 2}$ was at least twice the calculated value of $t_{1 / 2}$.

Values that did not meet these criteria were reported as approximations. $C_{\max }$ and $A U C$ values were also normalized to a dose of $1 \mathrm{mg} / \mathrm{kg}$.

A descriptive statistical analysis was performed (mean values and standard deviations). A 1-way ANOVA was performed for the dose-normalized values of $C_{\max }$ and area under the curve ( $A U C_{\text {last }}$ ) for each compound to determine a possible statistical difference between the various compounds.

\section{Stability Program}

OMS capsules containing fenofibrate $(33.5 \mathrm{mg})$ were stored at $25^{\circ} \mathrm{C} / 60 \%$ relative humidity $(\mathrm{RH})$ and $40^{\circ} \mathrm{C} / 75 \% \mathrm{RH}$ in both open and closed conditions. After 1, 2, and 6 months of storage, the formulation was evaluated for in vitro release (Hanson Vision ${ }^{\circledR}$ Elite 8) and the absence of crystallinity (differential scanning calorimetry [DSC], Mettler-Toledo DSC 822e; Mettler-Toledo, Zaventem, Belgium). For the purpose of the thermal analysis, about 3-4 $\mathrm{mg}$ of the sample was placed in DSC aluminum pans and heated from -30 to $150^{\circ} \mathrm{C}$ with constant heating rate of $10^{\circ} \mathrm{C} / \mathrm{min}$.

\section{Results and Discussion}

In this study, 2 OMS formulations-Formac capsules, with different content of fenofibrate (33.5 and $16.75 \mathrm{mg}$ ), were compared with 2 referent systems Lipanthyl ${ }^{\circledR}$ and Tricor ${ }^{\circledR}$ in terms of in vitro release and systemic exposure of fenofibrate and its metabolite when administered orally to dogs. The release profiles of the examined concepts are presented in Figure 1. The amount released of fenofibrate from the nanosized product Tricor ${ }^{\circledR}$ was $7.50 \mathrm{mg}$ after $5 \mathrm{~min}$. After $15 \mathrm{~min}$, a steady state was reached and lasted to the end of the experiment. The microsized product Lipanthyl ${ }^{\circledR}$ showed initial burst release with only $0.40 \mathrm{mg}$ released after $5 \mathrm{~min}$, reflecting very low solubility of the drug. It reached its maximum release after $120 \mathrm{~min}$. On the other hand, OMS capsule containing the same amount of fenofibrate ( $33.5 \mathrm{mg}$ ) had higher initial burst release $(0.72 \mathrm{mg}$ after $5 \mathrm{~min}$ ). The progress of the OMS capsule (eq. $16.75 \mathrm{mg}$ ) followed OMS capsule (eq. $33.5 \mathrm{mg}$ ) but with approximately 2-fold lower concentrations at each time point. At the end of the experiment, the amount of fenofibrate released from Lipanthyl ${ }^{\circledR}$ and Tricor $^{\circledR}$ was approximately 30\% from the initial dose. Both OMS capsules containing 33.5 and $16.75 \mathrm{mg}$ of fenofibrate attained a relatively high release of $66 \%$ and $60 \%$ of their dose, respectively. These data clearly illustrate that the slow dissolution kinetics and low water solubility of fenofibrate from the marketed products could be overcome by loading it into OMS.

Beagle dogs were selected to examine whether the fast in vitro release kinetics can be translated into an increased bioavailability of the drug. The animals were dosed orally with fenofibrate at a dose level of 33.5 (Lipanthyl ${ }^{\mathbb{R}}$ ), 16.75 (OMS-based formulation), 33.5 (OMS-based formulation), and 48 (Tricor ${ }^{\circledR}$ ) $\mathrm{mg} /$ animal in periods $1,2,3$ and 4, respectively (Table 2). During the study period, no mortality occurred. Body weight of the Beagle dogs was not significantly changed. There were no clinical signs noted during the observation period. Single doses of fenofibrate-OMS were safe and well tolerated. No relevant differences in safety and tolerability profile were observed when comparing a single dose of fenofibrate-OMS with Lipanthyl ${ }^{\mathbb{R}}$ and Tricor $^{\mathbb{R}}$. 

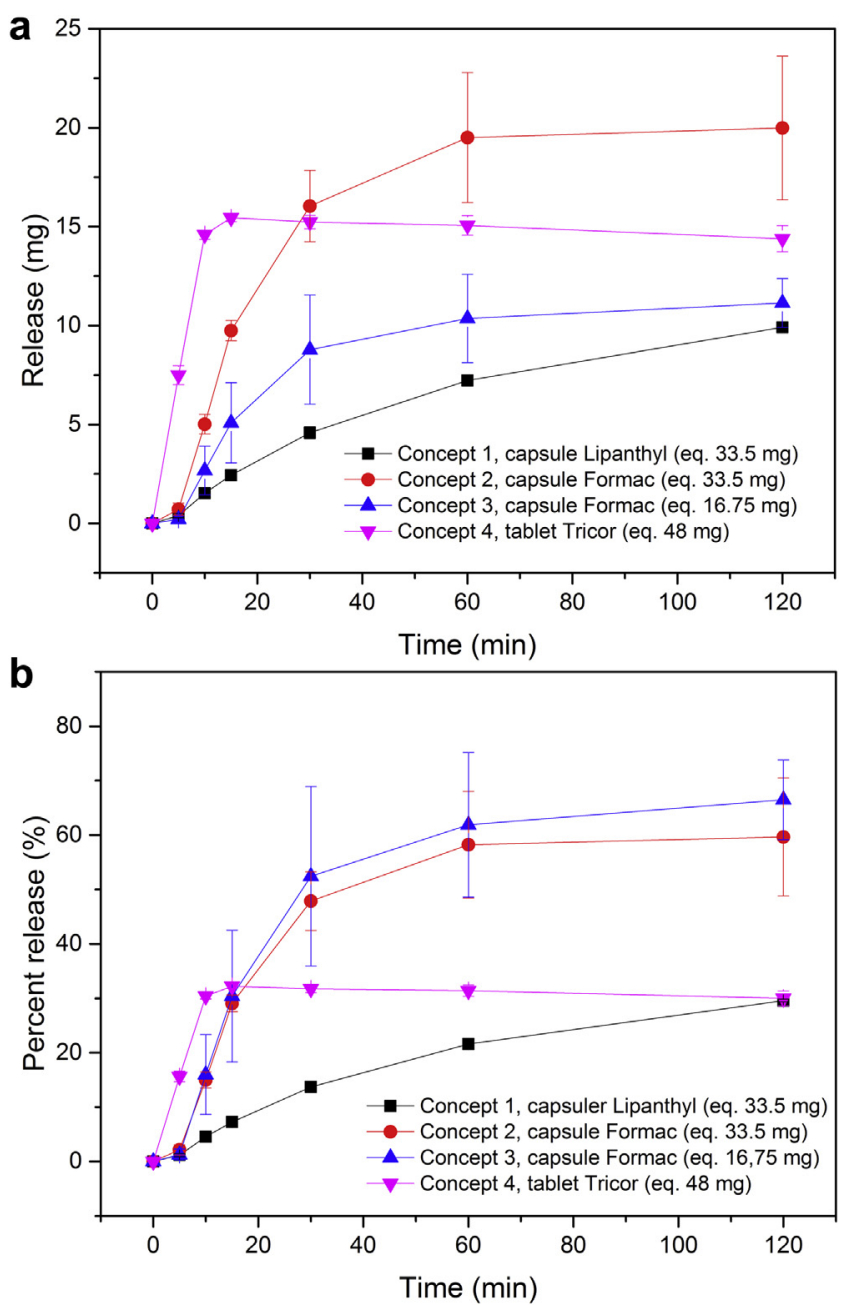

Figure 1. Dissolution/release experiments of Lipanthyl ${ }^{\circledR}$, Tricor $^{\circledR}$, and 2 OMS capsules in $900 \mathrm{~mL}$ of $0.1 \mathrm{~N} \mathrm{HCl}+0.1 \%$ Tween 80: (a) released amounts in milligrams and (b) percent of the original form released. Results are mean \pm standard deviation of 3 experiments.
Figure 2 shows the average plasma concentrations versus time curves of fenofibrate and the active metabolite fenofibric acid after dosing. Low concentrations of fenofibrate were measured in plasma, with several peaks. Statistical analysis on the rate and extent of absorption were performed on the dose-normalized data. This dose normalization was justifiable due to the demonstrated dose proportionality in the present study between a 16.5-mg and 33.5-mg fenofibrate after oral administration. The mean systemic exposure for fenofibrate expressed as dose-normalized $\mathrm{AUC}_{\text {last }}$ was $0.04,0.39,1.03$, and $0.88 \mathrm{~h} \mathrm{ng} / \mathrm{mL}$ for the consecutive periods after oral dosing of fenofibrate. Mean dose-normalized $\mathrm{C}_{\max }$ was 0.056 , $0.399,0.249$, and $0.477 \mathrm{ng} / \mathrm{mL}$ for periods $1-4$, respectively. The mean systematic exposure for fenofibric acid expressed as dosenormalized $\mathrm{AUC}_{\text {last }}$ was 736, 2440, 2780, and $2750 \mathrm{~h} \mathrm{ng} / \mathrm{mL}$ for the consecutive periods after oral dosing of fenofibrate. After oral dosing, $\mathrm{t}_{\max }$ was fast, varying between 0.5 and $2.0 \mathrm{~h}$ after dosing. Mean dose-normalized $C_{\max }$ was $145,623,524$, and $562 \mathrm{ng} / \mathrm{mL}$ for periods $1-4$, respectively. After oral dosing of fenofibrate, the interindividual variation in the $\mathrm{PK}$ parameters, as evaluated by coefficient of variation, was low to moderate: $38 \%-67 \%, 25 \%-31 \%$, $31 \%-62 \%$, and $10 \%-43 \%$ for periods $1-4$, respectively.

As it may be observed from the presented data, the total exposure to fenofibrate and fenofibric acid, expressed as $A_{U C} C_{\text {last }}$ values, between the 4 different compounds was comparable between fenofibrate-loaded OMS capsules (16.75 mg and $33.5 \mathrm{mg}$ ) and Tri$\operatorname{cor}^{\circledR}$ (period 2, 3, and 4) and was approximately a factor 3.5 higher in comparison with Lipanthyl ${ }^{\circledR}$ (period 1). The extent of absorption expressed as the dose-normalized $\mathrm{AUC}_{\text {last }}$ was higher for fenofibrate-OMS (eq $33.5 \mathrm{mg}$ ) than that for the marketed formulations Lipanthyl ${ }^{\circledR}$ and Tricor ${ }^{\circledR}$. Though some variability of the in vivo data, fenofibrate-OMS formulations show potential to improve bioavailability of fenofibrate. Consequently, the fenofibrate-OMS formulation (eq. $33.5 \mathrm{mg}$ ) whose PK profile of fenofibrate and its active metabolite fenofibric acid is confirmed (Figs. 2a and 2b), with proven safety and satisfying tolerability, is a promising candidate to be further investigated in a clinical trial setting.

Figure 3, which represents the release rate during stability testing (all conditions, 1, 2, and 6 month time points), shows that the release profiles of OMS-based formulation remained unchanged in all the examined conditions within 6 months. Results from the DSC

Table 2

Plasma Concentrations of Fenofibrate and Fenofibric Acid of the Different Concepts

\begin{tabular}{|c|c|c|c|c|}
\hline Data & Lipanthyl $^{\circledR}$ & OMS Capsule 16.75 mg & OMS Capsule $33.5 \mathrm{mg}$ & Tricor $^{\circledR}$ \\
\hline \multicolumn{5}{|c|}{ Fenofibrate pharmacokinetic data } \\
\hline Dose level (mg/kg) & $2.96 \pm 0.119$ & $1.48 \pm 0.064$ & $2.97 \pm 0.105$ & $4.28 \pm 0.131$ \\
\hline $\mathrm{t}_{\text {last }}(\mathrm{h})$ & $1.5-2.0^{\mathrm{a}}$ & $1.5-6.0^{\mathrm{a}}$ & $4.0-12.0^{\mathrm{a}}$ & $4.0-12.0^{\mathrm{a}}$ \\
\hline $\mathrm{t}_{\max }(\mathrm{h})$ & $1.0-2.0^{\mathrm{a}}$ & $1.0-1.5^{\mathrm{a}}$ & $1.0-8.0^{\mathrm{a}}$ & $0.5-4.0^{\mathrm{a}}$ \\
\hline $\mathrm{C}_{\max }(\mathrm{ng} / \mathrm{mL})$ & $0.163 \pm 0.092$ & $0.591 \pm 0.393$ & $0.733 \pm 0.476$ & $1.99 \pm 2.69$ \\
\hline $\mathrm{C}_{\max }{ }^{\mathrm{b}}([\mathrm{kg} \mathrm{ng}] /[\mathrm{mL} \mathrm{mg}])$ & $0.056 \pm 0.033$ & $0.399 \pm 0.242$ & $0.249 \pm 0.162$ & $0.477 \pm 0.65$ \\
\hline $\mathrm{C}_{\text {last }}(\mathrm{ng} / \mathrm{mL})$ & $0.098 \pm 0.099$ & $0.048 \pm 0.024$ & $0.111 \pm 0.104$ & $0.048 \pm 0.019$ \\
\hline $\mathrm{AUC}_{\text {last }}(\mathrm{h} \mathrm{ng} / \mathrm{mL})$ & $0.117 \pm 0.065$ & $0.58 \pm 0.38$ & $3.0 \pm 2.52$ & $3.70 \pm 3.66$ \\
\hline $\mathrm{AUC}_{\text {last }}{ }^{\mathrm{b}}$ (h kg ng/mL/mg) & $0.04 \pm 0.023$ & $0.39 \pm 0.26$ & $1.03 \pm 0.873$ & $0.88 \pm 0.883$ \\
\hline \multicolumn{5}{|c|}{ Fenofibric acid pharmacokinetic data } \\
\hline Dose level (mg/kg) & $2.96 \pm 0.119$ & $1.48 \pm 0.064$ & $2.97 \pm 0.105$ & $4.28 \pm 0.131$ \\
\hline $\mathrm{t}_{\text {last }}(\mathrm{h})$ & $12-24^{\mathrm{a}}$ & 24.0 & 24.0 & 24.0 \\
\hline $\mathrm{t}_{\max }(\mathrm{h})$ & $1.0-1.5^{\mathrm{a}}$ & $0.5-1.5^{\mathrm{a}}$ & $1.0-1.5^{\mathrm{a}}$ & $0.5-2.0^{\mathrm{a}}$ \\
\hline $\mathrm{C}_{\max }(\mathrm{ng} / \mathrm{mL})$ & $433 \pm 169$ & $922 \pm 283$ & $1560 \pm 892$ & $2410 \pm 1030$ \\
\hline $\mathrm{C}_{\max }{ }^{\mathrm{b}}([\mathrm{kg} \mathrm{ng}] /[\mathrm{mL} \mathrm{mg}])$ & $145 \pm 54.6$ & $623 \pm 190$ & $524 \pm 294$ & $562 \pm 233$ \\
\hline $\mathrm{C}_{\text {last }}(\mathrm{ng} / \mathrm{mL})$ & $86.7 \pm 107$ & $64 \pm 25$ & $154 \pm 74.3$ & $233 \pm 152$ \\
\hline $\mathrm{AUC}_{\text {last }}(\mathrm{h} \mathrm{ng} / \mathrm{mL})$ & $2200 \pm 1460$ & $3600 \pm 905$ & $8210 \pm 2490$ & $11,800 \pm 1170$ \\
\hline $\mathrm{AUC}_{\text {last }}{ }^{\mathrm{b}}$ (h $\left.\mathrm{kg} \mathrm{ng} / \mathrm{mL} / \mathrm{mg}\right)$ & $736 \pm 482$ & $2440 \pm 629$ & $2780 \pm 854$ & $2750 \pm 278$ \\
\hline $\mathrm{AUC}_{\infty}(\mathrm{h} \mathrm{ng} / \mathrm{mL})$ & $1550^{c}$ & $5190^{c}$ & $13,000^{c}$ & 13,400 \\
\hline AUC $_{\infty}{ }^{\mathrm{b}}(\mathrm{h} \mathrm{kg} \mathrm{ng} / \mathrm{mL} / \mathrm{kg})$ & $512^{\mathrm{c}}$ & $3450^{c}$ & $4440^{c}$ & $3110^{c}$ \\
\hline $\mathrm{t}_{1 / 2}(\mathrm{~h})$ & $10.9^{c}$ & $14.1^{\mathrm{c}}$ & $18.2^{\mathrm{c}}$ & $8.71^{c}$ \\
\hline
\end{tabular}

\footnotetext{
a Range.

b Dose normalized to $1 \mathrm{mg} / \mathrm{kg}$.

c Approximation.
} 
a

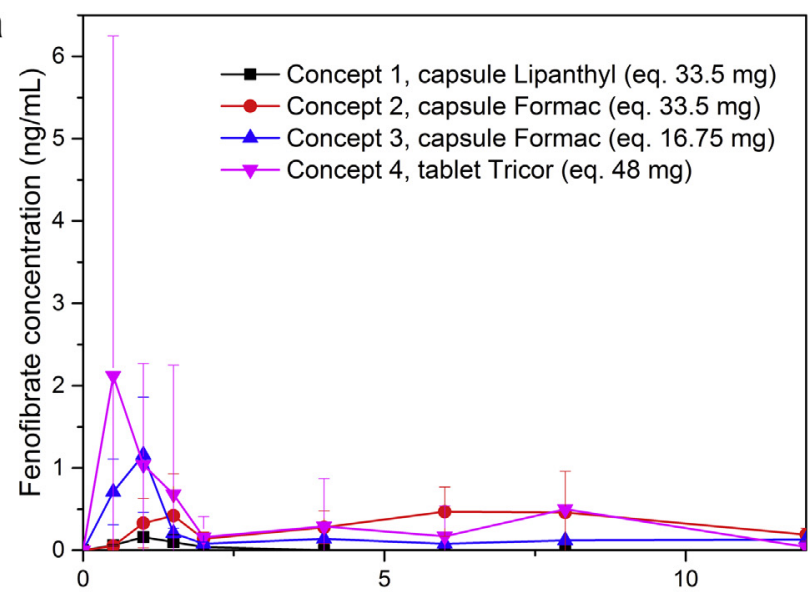

b

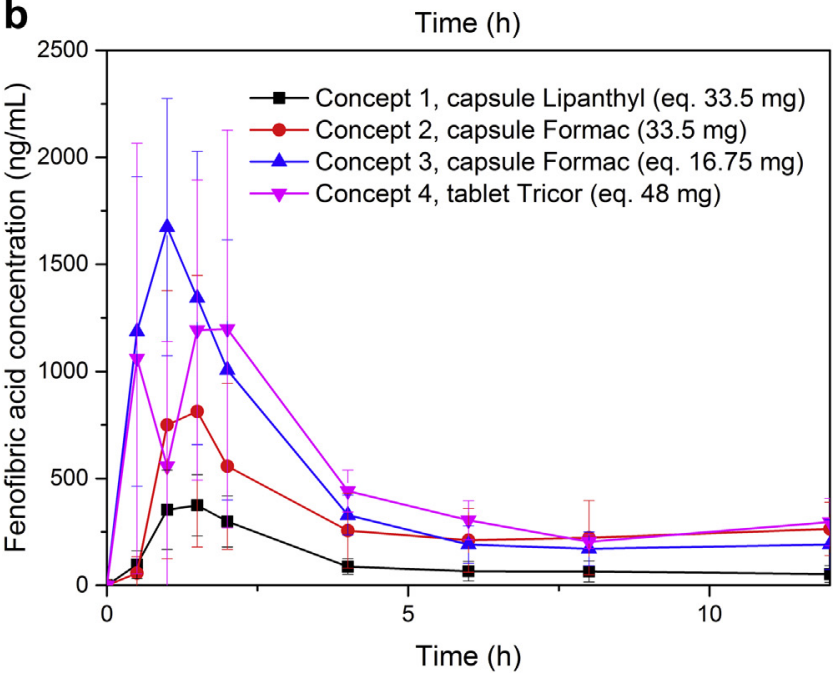

Figure 2. (a) Average plasma concentration versus time curves of fenofibrate after single dosing in male Beagle dog. (b) Average plasma concentration versus time curves of fenofibric acid after metabolization of fenofibrate. (The concentrations are normalized to $33.5 \mathrm{mg}$ ). Results are mean \pm standard deviation obtained from 4 animals.

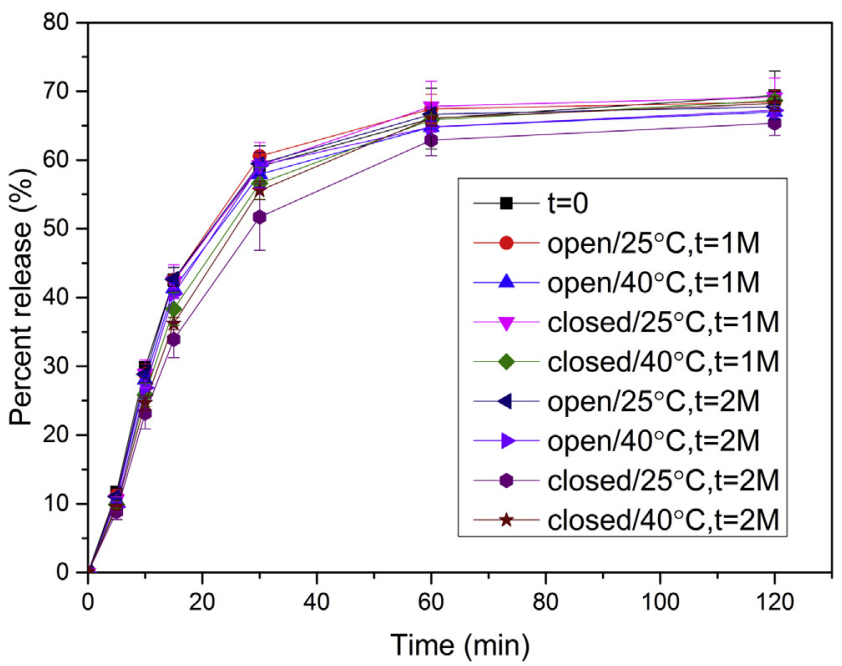

Figure 3. Dissolution/release experiments of stability samples of OMS powder $(n=3$; eq. $33.5 \mathrm{mg}$ of fenofibrate) in $900-\mathrm{mL}$ simulated gastric fluid + Tween 80 . Results are mean \pm standard deviation of 3 experiments. measurements showed absence of any crystallinity during the whole stability period. These results that support the unique stability properties of the silica technology are in accordance with the previously reported findings regarding ezetimibe-loaded OMS.

\section{Conclusion}

In the present study, the ability of OMS material to improve biopharmaceutical performance of poorly soluble compound fenofibrate was confirmed in vitro. In vivo study in dogs revealed PK profile of fenofibrate and its active metabolite fenofibric acid after oral administration of fenofibrate-OMS formulations. This study indicative of the potential of OMS-based formulations to improve bioavailability of fenofibrate revealed good tolerability and satisfying safety level of the used dose (eq. $33.5 \mathrm{mg}$ ) of fenofibrate in this highly stable formulation and opened the possibility for its further in vivo testing in humans.

\section{Acknowledgments}

This study was financially supported by Formac Pharmaceuticals NV, Gaston Geenslaan 1, B-3001 Leuven, Belgium.

\section{References}

1. Guay D. Micronized fenofibrate: a new fibric acid hypolipidemic agent. Ann Pharmacoter. 1993;33(10):1083-1103.

2. Genest JJ, Nguyen NH, Theroux P, Davignon J, Cohn JS. Effect of micronized fenofibrate on plasma lipoprotein levels and hemostatic parameters on hypertrigliceridemic patients with low levels of high density lipoprotein cholesterol in the fed and fasted state. J Cardiovasc Pharmacol. 2000;35(1):164-172.

3. Ming-Thau S, Ching-Min Y, Sokoloski TD. Characterization and dissolution of fenofibrate solid dispersion systems. Int J Pharm. 1994;103(2):137-146.

4. Yousaf AM, Kim DW, Oh YK, Yong CS, Kim YO, Choi HG. Enhanced oral bioavailability of fenofibrate using polymeric nanoparticulated systems: physicochemical characterization and in vivo investigation. Int J Nanomed. 2015;10:1819-1830.

5. Hens B, Brouwers J, Corsseti M, Augustins P. Gastrointestinal behavior of nanoand microsized fenofibrate: in vivo evaluation in man and in vitro simulation by assessment of the permeation potential. Eur J Pharm Sci. 2015;77:40-47.

6. Chen Y, Lu Y, Chen J, et al. Enhanced bioavailability of the poorly water-soluble drug fenofibrat by using liposomes containing a bile salt. Int J Pharm. 2009;376:153-160.

7. Fei Y, Kostewicz ES, Sheu MT, Dressman JB. Analysis of the enhanced oral bioavailability of fenofibrate lipid formulations in fasting humans using an in vitro-in silico-in vivo approach. Eur J Pharm Sci. 2013;85:1274-1284.

8. Xu W, Riikonen J, Lehto VP. Mesoporous systems for poorly soluble drugs. Int J Pharm. 2013;453:181-197.

9. Mellaerts R, Mols R, Jammaer JAG, et al. Increasing the oral bioavailability of the poorly water soluble drug itraconazole with ordered porous material. Eur J Pharm Biopharm. 2008;69:223-230.

10. Vialpando M, Backhujis F, Martens JA, Mooter GV. Risk assessment of premature drug release during wet granulation of ordered mesoporous silica loaded with poorly soluble compounds itraconazole, fenofibrate, naproxen and ibuprofen. Eur J Pharm Biopharm. 2012;81:190-198.

11. Van Speybroeck M, Bariallaro V, Do Thi T, et al. Ordered mesoporous silica material SBA-15: a broad spectrum formulation platform for poorly soluble drugs. J Pharm Sci. 2009;98:2648-2658.

12. Mellaerts R, Aerts CA, Van Humbeeck J, Augustijns P, Van den Mooter G, Martens J. Enhanced release of itraconazole from ordered mesoporous SBA-15 silica materials. Chem Commun. 2007;13:1375-1377.

13. Kiekens F, Eelen S, Verheyden L, Daems T, Martens J, Van den Mooter G. Use of ordered mesoporous silica to enhance the oral bioavailability of ezetimibe in dogs. J Pharm Sci. 2011;101:1136-1144.

14. Dressman JB, Herbert E, Wieber A, Birk G, Saal C, Lubda D. Mesoporous silicabased dosage forms improve release characteristics of poorly soluble drugs: case example fenofibrate. I Pharm Pharmacol. 2015;68(5):1-12.

15. Fei Y, Herbert E, Wieber A, et al. Evaluation of the dissolution behaviour of novel fenofibrate silica formulations in preprandial biorelevant media. AAPS Poster M1189, AAPS Annual Meeting, San Antonio, Texas. 2013. Available at: http:// abstracts.aaps.org/Verify/aaps2013/postersubmissions/M1189.pdf. Accessed September 6, 2015.

16. Van Speybroeck M, Mellaerts R, Mols R, et al. Enhanced absorption of the poorly soluble drug fenofibrate by tuning its release rate from ordered mesoporous silica. Eur J Pharm Sci. 2010;41:623-630.

17. Jammaer J, Aerts CA, D'Haen J, Won Seob J, Martens J. Convenient synthesis of ordered mesoporous silica at room temperature and quasi-neutral pH. J Mater Chem. 2009;19:8290-8293. 